\title{
Accuracy of venous blood oxygen pressure depends on arterial blood oxygen pressure
}

\section{To the Editors:}

I read with interest the article by REES et al. [1]. Their data on 40 patients with chronic lung disease supports the use of peripheral venous blood for an estimate of the arterial oxygen tension $\left(\mathrm{Pa}, \mathrm{O}_{2}\right)$ in a vast majority of patients. They also address this issue in a similar study [2]. They found that mean $\mathrm{Pa}_{2} \mathrm{O}_{2}$ was not clinically larger than the peripheral venous oxygen tension $(0.83 \pm 4 \mathrm{mmHg}$ or $0.11 \pm 0.53 \mathrm{kPa})$. They also showed that peripheral venous carbon dioxide tension and $\mathrm{pH}$ correlate very well with arterial values, with the arterial values being slightly lower and clinically negligible compared with venous values for carbon dioxide tension $(-0.7 \pm 2.1 \mathrm{mmHg}$ or $-0.09 \pm 0.28 \mathrm{kPa})$ and $\mathrm{pH}(-0.001 \pm 0.013)[1]$.

I would like to offer two comments on their findings. First, the authors describe accuracy (bias) as the mean difference between the two samples. However, true mean bias is best taken as the mean absolute difference between the two samples. Suppose, for example, that one subject has a $\mathrm{Pa}, \mathrm{O}_{2}$ that is $5 \mathrm{mmHg}$ more than the venous sample, and another subject has a $\mathrm{Pa}_{1} \mathrm{O}_{2}$ that is $5 \mathrm{mmHg}$ less. In such a case, if one uses mean difference instead of absolute mean difference, one would erroneously conclude that the accuracy of peripheral venous blood to predict $\mathrm{Pa}, \mathrm{O}_{2}$ is perfect (mean bias would be $0 \mathrm{mmHg}$ ), when in fact it is not. The authors calculate that the bias from their samples is $0.83 \mathrm{mmHg}(0.11 \mathrm{kPa})$. However, as the above example indicates, the absolute bias may well be much larger.

Secondly, the findings are of no surprise. A recent metaanalysis of 29 studies indicates that the accuracy of predicting $\mathrm{Pa}_{1} \mathrm{O}_{2}$ from a venous sample depends on the arterial sample [3]. While the meta-analysis compared earlobe and fingertip capillary samples to arterial samples, the findings of the meta-analysis still apply, since venous sampling is evaluated in both cases. The meta-analysis clearly shows that as the $\mathrm{Pa}, \mathrm{O}_{2}$ drops, as in the case of altitude or other pathophysiology (i.e. lung disease), the accuracy in predicting $\mathrm{Pa}_{\mathrm{a}_{2}} \mathrm{O}_{2}$ improves [3]. The meta-analysis thus clarifies why the Mount Everest study [4], and any study using diseased patients with low $\mathrm{Pa}_{\mathrm{a}_{2}} \mathrm{O}_{2}$ (e.g. DAR et al. [5]), supports the use of capillary blood to represent $\mathrm{Pa}, \mathrm{O}_{2}$, and any other study that uses subjects with normal $\mathrm{Pa}_{1} \mathrm{O}_{2}$ values does not. The data of REEs et al. [1] support the notion that peripheral venous blood reflects $\mathrm{Pa}, \mathrm{O}_{2}$ because patients had low a mean $\mathrm{Pa}_{\mathrm{a}} \mathrm{O}_{2}(67 \mathrm{mmHg}$ or $9 \mathrm{kPa}$ ) to begin with, and a low $\mathrm{Pa}, \mathrm{O}_{2}$ minimises the arterio-venous difference for oxygen tension, improving its accuracy in predicting $\mathrm{Pa}_{\mathrm{a}} \mathrm{O}_{2}$. In table 7 of the meta-analysis the regression equation indicates that when arterial $\mathrm{Pa}, \mathrm{O}_{2}$ is $67 \mathrm{mmHg}$, the mean difference between arterial and earlobe oxygen tension is small $\left(0.79 \mathrm{mmHg} ; \mathrm{r}^{2}=0.86\right.$, mean square error $4.8 \mathrm{mmHg}$ ) [3]. This difference is nearly identical to the $0.83 \mathrm{mmHg}$ mean difference from REES et al. [1] when using the same mean $\mathrm{Pa}_{\mathrm{a}} \mathrm{O}_{2}$.

Consistent with the recent work of REES and co-workers [1, 2], the meta-analysis demonstrated that venous sampling from an earlobe or fingertip could accurately reflect arterial $\mathrm{pH}$ or arterial carbon dioxide tension $\left(\mathrm{Pa}_{\mathrm{a}} \mathrm{CO}_{2}\right)$ over a wide range of values [3]. Therefore, sampling either peripheral venous blood, arterialised capillary blood from the earlobe, or fingertip capillary blood for predicting $\mathrm{Pa}_{\mathrm{a}} \mathrm{CO}_{2}$ or arterial $\mathrm{pH}$ is very robust over a wide range of clinical values. I would recommend substituting arterial sampling for venous sampling if one only wants to predict arterial $\mathrm{pH}$ or $\mathrm{Pa}, \mathrm{CO}_{2}$.

For predicting $\mathrm{Pa}_{1} \mathrm{O}_{2}$, venous blood sampling from a peripheral vein or from an earlobe sample (which is better than a fingertip sample) is only appropriate for conditions where the $\mathrm{Pa}_{\mathrm{a}_{2}} \mathrm{O}_{2}$ is low. The conundrum is, of course, that one cannot know if $\mathrm{Pa}_{\mathrm{a}} \mathrm{O}_{2}$ is low (i.e. $<70 \mathrm{mmHg}$ ) unless it is actually measured from an arterial sample. As the residual standard error in predicting $\mathrm{Pa}_{1} \mathrm{O}_{2}$ from venous samples is large, from $6 \mathrm{mmHg}$ when predicting from earlobe sampling (which is similar to their peripheral venous sampling data) to $15 \mathrm{mmHg}$ when predicting from fingertip sampling [3], I would recommend against using venous blood to predict $\mathrm{Pa}_{\mathrm{a}_{2}} \mathrm{O}_{2}$ or the alveolar to arterial oxygen tension difference in patients or in research subjects.

\section{G.S. Zavorsky}

Dept of Pharmacological and Physiological Science, and Dept of Obstetrics, Gynecology and Women's Health, Saint Louis University, School of Medicine, Saint Mary's Health Center, Saint Louis, MO, USA.

Correspondence: G.S. Zavorsky, Dept of Obstetrics, Gynecology and Women's Health, School of Medicine, Saint Louis University, 6420 Clayton Road, Rm 290, Saint Louis, MO 63117, USA. E-mail: zavorsky@slu.edu

Statement of Interest: None declared.

\section{REFERENCES}

1 Rees SE, Hansen A, Toftegaard M, et al. Converting venous acidbase and oxygen status to arterial in patients with lung disease. Eur Respir J 2009; 33: 1141-1147.

2 Toftegaard M, Rees SE, Andreassen S. Evaluation of a method for converting venous values of acid-base and oxygenation status to arterial values. Emerg Med J 2009; 26: 268-272. 
3 Zavorsky GS, Cao J, Mayo NE, et al. Arterial versus capillary blood gases: a meta-analysis. Respir Physiol Neurobiol 2007; 155: 268-279.

4 Barry PW, Mason NP, Collier D. Sampling for analysing blood gas pressures. Mount Everest study supports use of capillary samples. BMJ 1995; 310: 1072.

5 Dar K, Williams T, Aitken R, et al. Arterial versus capillary sampling for analysing blood gas pressures. BMJ 1995; 310: 24-25.

\section{DOI: 10.1183/09031936.00097909}

\section{From the author:}

In his letter, G.S. Zavorsky provides a summary of the results of the study of REES et al. [1] and two criticisms, the first related to the correctness of the statistical methods and the second related to the novelty of the results.

In summarising the results, he incorrectly states that the study of REES et al. [1] compares arterial and peripheral values of oxygen tension, carbon dioxide tension and $\mathrm{pH}$. In fact this [1] and a similar previous [2] study evaluate a method for calculating arterial gas tension values from peripheral venous blood [3], the comparisons performed being between measured and calculated values, as illustrated in figure 2 of our manuscript [1].

In response to G.S. Zavorsky's criticism concerning statistical methods, it is important to understand that the standard statistical method for comparing two measures of the same variable is Bland-Altman analysis [4], and it is this which had been used to compare calculated and measured values [1,2]. For the critics of this method [5], standard regression analysis was also included in the article by REES et al. [1]. In the Bland-Altman method, one uses the mean difference between the variables as a measure of accuracy, i.e. the systematic variation, and the standard deviation of the difference as a measure of the precision, i.e. the random variation. Therefore, if one subject has a measured arterial oxygen tension $\left(\mathrm{Pa}_{\mathrm{a}} \mathrm{O}_{2}\right) 1 \mathrm{kPa}$ higher than the calculated arterial oxygen tension $\left(\mathrm{Pca}_{\mathrm{ca}} \mathrm{O}_{2}\right)$ and another subject has a $\mathrm{Pa}_{\mathrm{a}} \mathrm{O}_{2} 1 \mathrm{kPa}$ less than $P_{\mathrm{ca}}, \mathrm{O}_{2}$, the mean difference indeed is zero, and this statistic is a useful representation of little systematic variation in the data, with random variation being characterised by the standard deviation of the difference. Calculation of the absolute mean difference, as proposed by G.S. Zavorsky, is not helpful as it would not effectively separate systematic and random variation.

G.S. Zavorsky comments that the results of the study [1] are of no surprise, relating his comment to his recent meta-analysis comparing arterial and capillary blood analysis [6]. In many regards it is satisfying that the results are not surprising, as this indicates that mathematical arterialisation is as good as mechanical arterialisation. In short, the capillary blood samples included in the meta-analysis have been mechanically arterialised [6]. This involves either administration of local vasodilation cream to, or warming of, the sampling site. Typically, there is a need to wait $10 \mathrm{~min}$ after application of the cream or for the sampling site to reach the correct temperature $[7,8]$, a procedure which has lead to development of special devices [9] and may indeed make clinical application rather cumbersome. In contrast, the previously presented [3] and evaluated [1, 2] method is a mathematical arterialisation where peripheral venous blood sampled in normal clinical practice is mathema- tically transformed into arterial values. For patients presenting in departments of emergency or pulmonary medicine, peripheral venous punctures are usually made for other blood samples, meaning that this technique could be readily integrated into current practice. In addition, the mathematical algorithm could be built into commercially available blood gas analysers, with the only extra overhead of the method being measurement of arterial oxygen saturation with a pulse oximeter $\left(\mathrm{Sp}, \mathrm{O}_{2}\right)$, which is required as input to the algorithm.

The need for $S_{p}, O_{2}$ as input to the algorithm can be seen as beneficial, in that it eliminates the conundrum postulated by G.S. Zavorsky. As shown by REES et al. [1], useful values of $\mathrm{Pa}, \mathrm{O}_{2}$ can be calculated in all situations in which $\mathrm{Sp}_{\mathrm{O}} \mathrm{O}_{2}$ is $\leqslant 96 \%$. In patients with $S p, O_{2}$ values $\geqslant 97 \%$, the method can still effectively be used to calculate arterial carbon dioxide tension and $\mathrm{pH}$, and it is safe to assume a clinically adequate $\mathrm{Pa}, \mathrm{O}_{2}$, despite the large errors in $\mathrm{Sp}_{\mathrm{P}} \mathrm{O}_{2}$ readings. While large scale studies are required, G.S. Zavorsky's recommendation against using venous blood to predict $\mathrm{Pa}_{\mathrm{a}} \mathrm{O}_{2}$ levels does not, therefore, appear justified, at least for the case of peripheral venous blood values transformed using mathematical arterialisation.

\section{S.E. Rees}

Correspondence: S.E. Rees, Center for Model-based Medical Decision Support, Aalborg University, Niels Jernes Vej 144-313, DK 9220 Aalborg East, Aalborg, Denmark. E-mail: sr@hst.aau.dk

Statement of Interest: A statement of interest for S.E. Rees can be found at www.erj.ersjournals.com/misc/statements.dtl

\section{REFERENCES}

1 Rees SE, Hansen A, Toftegaard M, et al. Converting venous acidbase and oxygen status to arterial in patients with lung disease. Eur Respir J 2009; 33: 1141-1147.

2 Toftegaard M, Rees SE, Andreassen S. Evaluation of a method for converting venous values of acid-base and oxygenation status to arterial values. Emerg Med J 2009; 26: 268-272.

3 Rees SE, Toftegaard M, Andreassen S. A method for calculation of arterial acid-base and blood gas status from measurements in the peripheral venous blood. Comput Methods Programs Biomed 2006; 81: $18-25$.

4 Bland JM, Altman DG. Statistical methods for assessing agreement between two methods of clinical measurement. Lancet 1986; 8476: 307-310.

5 Hopkins WG. Bias in Bland-Altman but not regression validity analysis. Sport Sci 2004; 8: 42-46.

6 Zavorsky GS, Cao J, Mayo NE, et al. Arterial versus capillary blood gases: a meta-analysis. Respir Physiol Neurobiol 2007; 155: 268-79.

7 Sauty A, Uldry C, Debétaz LF, et al. Differences in $\mathrm{PO}_{2}$ and $\mathrm{PCO}_{2}$ between arterial and arterialized earlobe samples. Eur Respir J 1996; 9: 186-189.

8 Zavorsky GS, Lands LC, Schneider W, et al. Comparison of fingertip to arterial blood samples at rest and during exercise. Clin J Sport Med 2005; 15: 263-270.

9 Zello GA, Smith JM, Pencharz PB, et al. Development of a heating device for sampling arterialized venous blood from a hand vein. Ann Clin Biochem 1990; 27: 366-372. 